\title{
Scheduling and Programming of Rapid Finger Sequences: Tests and Elaborations of the Hierarchical Editor Model
}

\author{
David A. Rosenbaum \\ School of Communications and Cognitive Science, \\ Hampshire College, and Department of Psychology, \\ University of Massachusetts
}

\author{
Van Hindorff and Edwin M. Munro \\ Hampshire College
}

\begin{abstract}
Is a response sequence executed only after the sequence has been fully programmed, as discrete processing models predict, or does execution begin before programming has been completed, as contınuous processing models predict? To address this issue, we tested a discrete processing model of human motor performance, the hierarchical editor model of Rosenbaum, Inhoff, and Gordon (1984) This model was developed to account for data from experiments in which people perform one of two possible finger sequences, depending on the identity of a choice signal The model assumes a hierarchically organized motor program that is first "edited" to resolve any uncertainties and is then "executed" to produce the desired responses Three experiments reported here show that, contrary to the model's predictions and some well-known motor programming results (Sternberg, Monsell, Knoll, \& Wright, 1978), the reaction tıme to begin a response sequence actually decreases with the length of the sequence under some choice conditions We account for these results with a model that allows execution to begin while editıng is still in progress A key assumption in the model is that subjects schedule execution so that means and variances of interresponse times are minimized
\end{abstract}

An influential source of support for the view that behavioral sequences are represented in detall prior to their execution is the finding that the reaction tıme (RT) to initiate a sequence of rapid responses increases with the length of the sequence. Henry and Rogers (1960) were the first to report this effect. They found that the simple RT to lift the hand from a button increased as additional responses were required. More recently, Sternberg, Monsell, Knoll, and Wright (1978) found that the simple RT to initiate a highly prepared string of typewritten or spoken responses increased with the number of elements in the string. Similar results have been obtained for handwriting ( Hulstijn \& van Galen, 1983) and saccadic eye movements (Zingale \& Kowler, 1985)

Sequence length effects have also been obtained for choice RTs (Inhoff, 1986, Klapp, Wyatt, \& Lingo, 1974; Rosenbaum, Saltzman, \& Kungman, 1984) In Rosenbaum et al.'s study, subjects performed one of two possible finger-tapping sequences in

Aspects of this study were reported at the Twenty-Fifth Annual MeetIng of the Psychonomic Society. San Antonio, Texas, 1984, and have been described informally in a brief communiqué by Rosenbaum, Hindorff, and Munro (1986)

This research was supported in part by National Science Foundation Grants BNS-8120104 and BNS-8408634 and Research Career Development Award IKO4 NS00942-01 from the National Institute of Neurological and Communicative Diseases and Stroke (to the first author)

The authors thank Don Fisher, Carol Fowler, Heather Jane Barnes, Judith Kroll, and three anonymous reviewers for their valuable comments on an earher version of this article

Correspondence concerning this article should be addressed to David A Rosenbaum, School of Communications and Cognitive Science, Hampshire College, Amherst, Massachusetts 01002 response to a discrimınative signal The responses were performed under the instruction to minımıze the tıme between appearance of the choice signal and completion of the required sequence. Choice RTs were longest when the choice was between sequences of three responses, shorter for sequences of two responses, and still shorter for sequences of one response each.

A model that can account for these results, as well as the simple RT results described above, holds that rapid series of responses are centrally controlled by successively decomposing their constituents into smaller and smaller units The procedure can be visualized as a tree-traversal process (see Rosenbaum, Kenny, \& Derr, 1983), in which the latency of each response is related to the length of the node path leading to the terminal node corresponding to that response According to this model, initial response latencies increase with sequence length because as sequences grow longer, the node path from the top of the tree to the left-most terminal also tends to grow (Rosenbaum, 1985). Similarly, because the mean path length within the tree tends to grow with sequence length, mean interresponse times also increase with sequence length, as has been observed both in simple (Sternberg et al., 1978) and chorce RT (Rosenbaum, Saltzman, \& Kingman, 1984) studies. ${ }^{1}$

Although the tree-traversal model characterizes the execution of response sequences, it is not a model of sequence chorce $A$ possible extension of the model is that subjects choose between trees to which the sequences correspond (Rosenbaum, Saltz-

\footnotetext{
'The tree-traversal model also uniquely predicts an inverted $U$ shaped serial position curve for interresponse times (see Rosenbaum, 1985), a result obtained by Sternberg, Monsell, Knoll, and Wright (1978) but not uniquely predicted by their "buffer search" model (see Sternberg et al , 1978, p 147)
} 
man, \& Kingman, 1984) This view is inadequate, however, because it does not account for chotce context effects. Consider one such effect reported by Rosenbaum, Inhoff, and Gordon (1984; Experıment 3) in which subjects chose between finger sequences of fixed length, where the first, second, or third response distinguished the two possible sequences In different blocks of trials, the choices were (a) $1 \mathrm{rm}$ versus Irm, (b) $1 \mathrm{rm}$ versus $1 R m$, or (c) irm versus $1 r M$, where $1, r$, and $m$ denote key presses of the left index, ring, and middle fingers, respectively, and $I, R$, and $M$ denote key presses of the right index, ring, and middle fingers, respectively. In Condition (a) the first response was uncertain, in Condition (b) the second response was uncertain, and in Condition (c) the third response was uncertain Rosenbaum, Inhoff, and Gordon found that the mean latency, $T_{1}$, of the first response in the common sequence (1rm) decreased as the position of the uncertain response receded from the beginning of the sequence If subjects had chosen between the sequences by deciding between two independent trees, the serial position of the uncertain response should have had no effect on $T_{1}$

To account for this result and others, Rosenbaum, Inhoff, and Gordon proposed an elaborated tree-traversal model, embodled in their hierarchical editor (HED) model of sequence choice performance. According to the HED model, two passes are made through a single motor program The first, "edit," pass ensures that any uncertainties are resolved. It proceeds to the first point of uncertainty before the reaction signal is presented, and after the reaction signal is identified, proceeds from that point to the end of the program (1.e., to the right-most terminal node of the tree). Once the edit pass has been completed, there is a second, "execution;" pass. As its name implies, the execution pass allows responses to be phystcally produced when their corresponding terminal nodes are encountered. The execution pass, like the edit pass, follows a tree-traversal process. Assuming that each extra node traversal takes extra time (both in the edit and execution passes), the HED model accounts for the data reviewed above

In the present article, we report experiments designed to test and elaborate the HED model The major result emerging from these experiments is that the time to initiate a sequence of motor responses actually decreases with the length of the sequence under certain conditions. In Experiment 1, we describe this effect and the background to its discovery. In Experiments 2 and 3 we report additional tests of a model that accounts for the phenomenon. In the General Discussion section we consider the implications of our work

\section{Experiment 1}

The HED model can be viewed as a discrete rather than a continuous processing model. In discrete processing models, a chunk of information is completely processed in one hypothesized stage before it begins to be processed in the next hypothesized stage (Sternberg, 1969). In contınuous processing models, one stage of processing may begin to work on a given chunk of information before the preceding stage has finished with it (McClelland, 1979). Because the HED model assumes that a motor program cannot be executed until the program has been completely edited, it is a discrete processing model
The discrete processing assumption of the HED model raises a potential problem. If a subject were asked to choose between two very long response sequences, an inordinately long time could elapse before the first response was performed Thus, if a pianist were asked to choose between two (prepared) piano concertos, it might be several minutes before the first note was played. As this example shows, there must be some hmit on the number of responses that are preprogrammed (Logan, 1983, Monsell 1986)

One solution to the span-of-programming problem is to assume that subjects break up the sequence to be performed into chunks, each of which is edited and executed in the manner proposed in the HED model. Under this condition, $T_{\mathrm{I}}$ would depend on the size of the initial chunk If the initial chunk happened to get smaller as the sequence lengthened, $T_{1}$ would decrease with sequence length. (We refer to this as an inverse length effect.) Similarly, if the initial chunk happened to get smalter as the distance to the first uncertain response increased, $T_{1}$ would also decrease with the serial position of the first uncertain response, as Rosenbaum, Inhoff, and Gordon (1984) reported. Thus if subjects applied the discrete processing system of the HED model to suitable subsequences of responses, $T_{1}$ could decrease with sequence length and the distance to the first uncertain response. The burden of explanation would be to show why the size of the initial chunk changed so as to produce these results

Another solution to the span-of-programming problem is to allow editing and execution to occur continuously, that is, to allow execution of the early responses of a sequence to began before the entire sequence has been edited. Such a continuous programming system could also give rise to an inverse length effect. To see how, consider an analogy to cooking. One goal of an experienced cook is to serve dishes in a particular order without undue delays between the dishes Because the cook knows that different dishes take different times to prepare, he or she begins with those that require longer preparation times before those that require shorter preparation times. In essence, the cook works backward from the desired serving times of the dishes to determune when preparation of the dishes should begin Working backward in this way is common in skalled performance. To hit an oncoming baseball, for example, the batter must time the initiation of the swing so that the bat and ball meet at a desired point in space and time (Bahill \& LaRitz, 1984). Similarly, in order for speech articulators with different masses or innervation delays to arrive at the same place at the same time, their respective actions must be initiated at precisely scheduled intervals (Lenneberg, 1967, chapter 3).

Suppose that subjects in sequence choice experiments adopt a sımılar "schedulıng" strategy. In particular, suppose they try to follow the instruction to perform the required sequence as quickly as possible by minimizing the mean and variance of interresponse times. If editing the uncertain response begins as soon as the reaction signal is identified, then the subject has to postpone execution of the earlier, certain responses to ensure that no extra delay occurs before execution of the response that was initially uncertain (provided editing takes much longer than execution). Let $u$ denote the serial position of the uncertain response, $s$ the time required to encode the reaction signal, $e$ the tıme used to edit the uncertain response after encoding the reac- 
tion signal, and $d$ the time needed to execute each response. When interresponse times are minimized to $d$, the uncertain response is produced at time $T_{u}=s+e+d$, response $u-1$ is produced at time $T_{u-1}=s+e$, response $u-2$ is produced at tıme $T_{u-2}=s+e-d$, and in general, response $u-\jmath(0 \leq \jmath \leq$ $u+1)$ is produced at time

$$
T_{u-\jmath}=s+e-(\jmath+1) d
$$

The latency of the first response $u=u-1$ ),

$$
T_{u-\jmath}=T_{1}=s+e-u d
$$

decreases as $u$ increases. This scheduling model assumes that editing occurs in parallel with execution, which contradicts the HED model's assumption that execution must follow editing. A major goal of the experiments reported here was to test this new model.

Before we turn to the experiments, we wish to consider two versions of the scheduling model Both versions assume that editıng and execution occur in parallel, and both models assume that successive responses are executed serially, that is, that successive responses are centrally triggered one after the other. The two versions of the scheduling model differ in terms of whether response subprograms are edited serially (as assumed in the HED model) or in parallel (contrary to the HED model) Both views are consistent with the hypothesis that execution occurs while editing is still going on The serial and parallel editing versions of the scheduling model have different consequences for response timing, however, as we shall show.

Consider the serial editing version of the scheduling model. Recall that in the HED model, we assumed that editing begins at the uncertain response and proceeds to the end of the sequence If this idea is applied to scheduling, $T_{1}$ should increase with the number of responses after the first response. The reason is that if initial responses are scheduled with respect to the target tume needed to complete the editing process, that target time will be $s+a e$, where $a$ is the number of responses after the uncertain response. The latency of the first response will therefore be

$$
T_{1}=s+a e-u d
$$

In other words, $T_{1}$ will be affected oppositely and independently by the number of responses before and after the uncertain response.

The alternative model, which holds that responses are edited in parallel, predicts that $u$ should be the sole determinant of $T_{1}$ That is, adding responses after the uncertain response should have no effect on $T_{1}$.

The first experiment tested these competing predictions. Note that if the results supported the serial programming version of the scheduling mode (Equation 3), they would discredit the discrete chunking model. The discrete chunking model claimed that if $T_{1}$ decreased as the sequence grew longer, this change would be attributable to decreases in the size of the first response chunk. On the basis of this model, we would not expect $T_{1}$ to depend on the number of responses after the uncerain response.

\begin{tabular}{|c|c|c|c|}
\hline \multirow[b]{2}{*}{ Choice } & \multicolumn{3}{|c|}{ No of responses } \\
\hline & $\begin{array}{l}\text { Before } \\
\text { uncertain } \\
\text { response }\end{array}$ & $\begin{array}{l}\text { After } \\
\text { uncertain } \\
\text { response }\end{array}$ & Total \\
\hline $\begin{array}{l}\mathrm{R} r \mathbf{1} \\
\mathbf{R} m_{1}\end{array}$ & 1 & 1 & 3 \\
\hline $\begin{array}{l}\text { Rr } l \\
\text { Rr } m\end{array}$ & 2 & 0 & 3 \\
\hline $\begin{array}{l}\text { RR } r 1 \\
\text { RR } m \mathbf{1}\end{array}$ & 2 & 1 & 4 \\
\hline $\begin{array}{l}\text { RRr } l \\
\text { RRr } m\end{array}$ & 3 & 0 & 4 \\
\hline $\begin{array}{l}\text { RRRR } r \mathrm{i} \\
\text { RRRR } m 1\end{array}$ & 4 & 1 & 6 \\
\hline $\begin{array}{l}\text { RRRRr } 1 \\
\text { RRRRr } m\end{array}$ & 5 & 0 & 6 \\
\hline
\end{tabular}

Table 1

Sequences Studied in Experiment I

Note Half of the subjects had the sequences listed here, and half had the left-right mirror image of these sequences ( $\mathrm{g}, \mathrm{rR} I$ vs $\mathrm{rR} M$, etc ) Italics denote uncertain responses The letters indicate key presses made with the following fingers $1=$ left index, $m=$ left middle, $r=$ left ring, and $\mathrm{R}=$ nght ring

\section{Method}

\section{Choices and Predictions}

The choices of the first experiment are listed in Table 1 Embedded in each was a choice between $\mathrm{r} 1$ and $\mathrm{ml}$ or between $\mathrm{r} 1$ and $\mathrm{rm}$ In the various conditions of the experiment these choices were preceded by one, two, or four key presses made with the right rng finger (R) The resultung design crossed the distance of the first uncertain response from the end of the sequence with the total length of the sequence

\section{Apparatus}

The experiment was controlled with an Apple II Plus computer equipped with a Cognitive Testıng Station (Digitry Corporatıon, Medford, Massachusetts) A black-and-white cathode-ray-tube (CRT) screen, located about $70 \mathrm{~cm}$ from the seated subject, was used to present the reaction signals, instructions, and feedback Responses were made on a keyboard consisting of six microswitches, each requiring about $120 \mathrm{~g}$ of static force and about a $2-\mathrm{mm}$ displacement for closure The microswitches were arranged so they could be comfortably depressed with the tips of the index, middle, and ring fingers of the left and right hands

\section{Procedure}

At the start of each block, the subject was told what the alternative response sequences would be for that block and what the corresponding choice signals would be After self-paced practice, the subject told the experimenter when he or she felt ready to begin the block

On each tnal the outline of a $10-\mathrm{cm}$ square appeared in the center of the screen, and at the same tume a brief, high-pitched warning tone sounded The square remained on the screen for $1 \mathrm{~s}$ Then, 050,075 . or $100 \mathrm{~s}$ after the square was erased, an $X$ or $O$ appeared at the location corresponding to the center of the square At the beginning of each block of trials, subjects were told which sequence was to be performed when the $X$ or $O$ appeared

The $X$ or $O$ remained on the screen until the required number of 
switch closures occurred, at which time a high- or low-pitched tone sounded, indicating that the performed sequence was elther correct or incorrect, respectively The sequence was considered incorrect if any response was out of order, if any extra responses occurred within 1 s of the final required response, if the time between the choice signal and first response was less than $01 \mathrm{~s}$, or if any response time exceeded $12 \mathrm{~s}$ After the trial was completed, the data were printed out within earshot of the subject Four seconds later, the next trial began These were 22 trials in each block

After completıng the block, the subject was shown a score that equaled the mean latency of all cor rect sequences plus the total number of incorrectly performed sequences multiplied by 50 , this coefficient was selected in earlier work for achieving error rates of less than $10 \%$ Subjects were told to try to minimize their scores by minimizing the tıme between the choice signal and the final response and by making as few errors as possible Monetary bonuses were awarded for obtainıng scores below prescribed minıma A short break was taken after the score was presented

\section{Design}

Half of the subjects were tested in the six conditions listed in Table 1, and half were tested in the mirror-image conditions (e g., rRI vs rRM, rRI vs rMI, etc) For half of the subjects in each group, the $X$ was consistently mapped to sequences that ended with the index finger, and for the other half the $O$ was consistently mapped to those sequences Each subject was tested in all six conditions in each of the 2 consecutive days of the experiment, the first day being for practice only The order in which the conditions were tested each day was based on a Latin square design Unknown to the subject, the first two trials of each block were for practice only

\section{Subjects}

Eight Hampshire College students participated for an hourly wage plus bonuses The students were pseudorandomly assigned to the four groups so that 2 subjects were in each group

\section{Results}

\section{Initıal Response Times}

Mean $T_{1}$ data from errorless trals (about $90 \%$ of the trials) on the second day of the experiment appear in Figure 1 These data were subjected to an analysis of variance (ANOVA) that tested the effects of number of responses (three, four, or six), distance of the uncertain response from the end of the sequence (one or zero), starting hand, (right or left), and subjects (4 in each starting-hand group). The effect of number of responses was statistically significant, $F(2,8)=13.65, p<.003$; mean values of $T_{1}$ were $456 \mathrm{~ms}, 398 \mathrm{~ms}$, and $377 \mathrm{~ms}$ for three-, four-, and six-response sequences, respectively. The effect of the position of the uncertain response was also statistically significant, $F(1,4)=1126, p<.03$; mean values of $T_{1}$ were $450 \mathrm{~ms}$ and $372 \mathrm{~ms}$ when the uncertain response occupted the next-to-last and the last serial position, respectively The interaction between number of responses and the position of the uncertain response was not statistically significant $(p>.40)$. Neither was the effect of starting hand, $F(1,4)=2.44, p>.15$, or any interactions involving starting hand (all $p s>.30$ ). In a second $A N$. Ova that did not include the starting hand as a factor, there was a highly significant effect of the position of the uncertan response, $F(1,7)=16.29, p<.005$, as well an effect of the num-

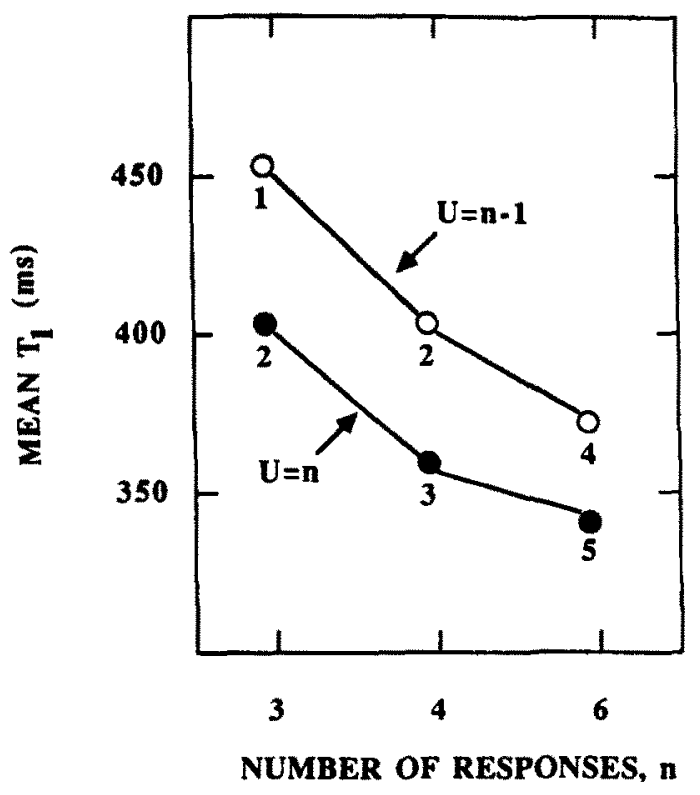

Figure I Mean latency $\left(T_{1}\right)$ of the first response in Expenment 1 (The two curves correspond to conditions in which the uncertain response occupied the last serial position $(U=n)$ or the next-to-last serial position $(U=n-1)$ The numbers next to the plotted points refer to the number of responses occurring before the uncertain response )

ber of responses, $F(2,14)=1520, p<.001$; again, there was no interaction between these two factors, $F(2,14)=1.01$, $p>.40$.

\section{Interresponse Times}

As shown in Table 2, mean interresponse tumes changed with serial position and number of responses In general, mean interresponse times decreased with serial position and increased with number of responses. These data were first analyzed by conducting ANOVAs restricted to sequences consisting of the same number of responses. The first ANOVA was restricted to the three-response sequences and tested the effects of the serial position of the performed response (second or third), the serial position of the uncertain response (second or third), starting hand (left or nght), and subjects nested in startıng-hand group (The analysis excluded the data of 1 subject whose interresponse times were extremely long compared with those of the other subjects.) The effect of the serial position of the uncertain response, though lange, was not statistically significant, $F(1$, $5)=1.49, p=.28$. Likewise, the interaction between the serial position of the uncertain response and the serial position of the performed response was not statistucally significant, $F(1,5)=$ $1.79, p=.24$. No other main effects or interactions approached statistical significance (all $p s>.50$ ).

The second ANOVA was restricted to four-response sequences and had the same design; the responses used were two, three, and four. $A$ hughly significant effect of response position emerged, $F(2,10)=13.42, p<.01$, so that mean latencies decreased with serial position. There were no other main effects or interactions in this ANOVA (all $p s>.10$ ). 
Table 2

Mean Interresponse Times (in Milliseconds)

From Experiment 1

\begin{tabular}{cccccccc}
\hline $\begin{array}{c}\text { Sequence } \\
\text { length }\end{array}$ & $\begin{array}{c}\text { Uncertain } \\
\text { response }\end{array}$ & $T_{2}$ & \multicolumn{1}{c}{$T_{3}$} & $T_{4}$ & $T_{5}$ & $T_{6}$ & $M$ \\
\hline \multirow{2}{*}{3} & 2 & 111 & 106 & - & - & - & 109 \\
& 3 & 68 & 80 & - & - & - & 74 \\
4 & 3 & 151 & 124 & 96 & - & - & 124 \\
& 4 & 160 & 116 & 84 & - & - & 120 \\
6 & 5 & 181 & 175 & 162 & 182 & 111 & 162 \\
& 6 & 174 & 164 & 159 & 178 & 114 & 158 \\
\hline
\end{tabular}

Note Italicized values indicate initially uncertain responses $T_{2}-T_{6}$ mean latencies of the 2nd-6th responses Dashes indicate undefined latencies, that is, latencies for responses past the end of the sequence

The final ANOVA in this series was restricted to the final five responses in the six-response condition. This ANOVA yielded a significant main effect of the serial position of the performed response, $F(4,20)=15.87, p<.001$, and a significant interaction between starting hand and serial position, $F(4,20)=3.03$, $p<05$, but there were no other main effects or interactions (all $p s>.30)$

Because the ANOVAs just described did not permit comparisons across conditions with different numbers of responses, another ANOVA was performed that used the data from the last two responses of all sequences ( $\mathrm{n}$ or $\mathrm{ml}$ for subjects in the righthand-first group, or RI or MI for subjects in the left-hand-first group) The factors were sequence length, startıng-hand group, position of uncertain response, and serial position of performed response. Sequence length had a significant effect on interresponse tımes, $F(2,10)=937 p<.01$, as did the serial position of the performed response, $F(1,5)=942, p<.03$; longer sequences had longer interresponse times, and the interresponse tıme of the next-to-last response was longer than the interresponse time of the last response. The interaction between these factors was also statistically significant, $F(2,10)=1157, p<$ .01 ; the longer the sequence, the larger the difference between the latencies of the last two responses. No other main effects or interactions emerged in this analysis (all ps > .10).

\section{Errors}

Errors occurred on $10.5 \%$ of the trials on the second day of the experiment; errors on the first day were not studied. The error proportions were subjected to an ANOVA that analyzed the effects of starting hand, position of uncertain response ( 0 or 1 removed from the sequence end), and sequence length (three, four, or six). Only one effect reached statistical significancethe interaction of all three factors, $F(2,10)=445, p<.05$ All other $p$ values exceeded .13 .

\section{Discussion}

Subjects in Experiment 1 chose between sequences with uncertain responses in the last or next-to-last serial position and with one, two, or four renditions of a single finger press preceding the final response parr. Mean $T_{1}$ decreased with sequence length and was longer when the uncertain response was in the next-to-last position than in the last serial position. These two effects were statistically independent.

The discovery of an inverse length effect for the time needed to initiate a response sequence constitutes a major exception to the well-known finding that initiation time increases with sequence complexity. We hypothesized such an outcome, however, by allowing that subjects might schedule the execution of early responses to coincide with decision making about later responses. We considered two versions of this scheduling model. One assumed that editing is a parallel process; the other assumed that editing is a serial process. According to the parallel version, subjects work backward from the first uncertain response in schedulıng earlier responses; according to the serial version, subjects edit all responses from the uncertain response onward and schedule earher responses so that the next-to-last response is executed just before the last response is ready for execution. Consistent with the serial model, $T_{1}$ depended on the number of responses both before and after the uncertain response.

The latter result vitiates another model we considered, which was an alternative to the scheduling model. According to this model, execution occurs only after editing has been completed, that is, that execution and editing follow the constraints of a discrete processing system rather than a contınuous processing

Table 3

Condttions and Mean Latencies (in Milliseconds) From Experiment 2

\begin{tabular}{|c|c|c|c|c|c|c|c|c|c|c|c|}
\hline \multirow[b]{2}{*}{ Condition ${ }^{*}$} & \multicolumn{2}{|c|}{ No of responses } & \multirow[b]{2}{*}{$T_{1}$} & \multirow[b]{2}{*}{$T_{2}$} & \multirow[b]{2}{*}{$T_{3}$} & \multirow[b]{2}{*}{$T_{4}$} & \multirow[b]{2}{*}{$T_{5}$} & \multirow[b]{2}{*}{$T_{6}$} & \multirow[b]{2}{*}{$T_{7}$} & \multirow[b]{2}{*}{$T_{8}$} & \multirow[b]{2}{*}{$T_{9}$} \\
\hline & $\begin{array}{c}\text { Before } \\
\text { uncertain } \\
\text { response }\end{array}$ & $\begin{array}{c}\text { After } \\
\text { uncertain } \\
\text { response }\end{array}$ & & & & & & & & & \\
\hline $\begin{array}{l}\text { A } \mathrm{mr} / \mathrm{mr} \\
\text { B } \mathrm{mr} / \mathrm{mrmr} \\
\text { C } \mathrm{mrmr} / \mathrm{mr} \\
\text { D } \mathrm{mr} / \mathrm{mrmrmr}\end{array}$ & $\begin{array}{l}2 \\
2 \\
4 \\
2\end{array}$ & $\begin{array}{l}2 \\
4 \\
2 \\
6\end{array}$ & $\begin{array}{l}296 \\
315 \\
288 \\
333\end{array}$ & $\begin{array}{l}172 \\
172 \\
180 \\
186\end{array}$ & $\begin{array}{l}212 \\
206 \\
250 \\
210\end{array}$ & $\begin{array}{l}177 \\
187 \\
177 \\
207\end{array}$ & $\begin{array}{l}177 \\
171 \\
232 \\
198\end{array}$ & $\begin{array}{l}- \\
227 \\
183 \\
226\end{array}$ & $\begin{array}{l}\overline{172} \\
194 \\
200\end{array}$ & $\frac{-}{242}$ & $\frac{-}{205}$ \\
\hline
\end{tabular}

Note The letters indicate key presses made with the following fingers $\mathrm{I}=$ right index, $\mathrm{m}=$ left middle, and $\mathrm{r}=$ left ring $T_{1}-T_{9}$ mean latencies of the 1st-9th responses

atalics denote uncertain responses The other possible response at this serial position was $M$ 
system Because this model predicted that changes in $T_{1}$ would be due to smaller initial production units, the number of responses after the uncertain response would not be expected to have any effect The fact that it did suggests that the discrete system was not used

In proposing the scheduling model, we assumed that subjects would try to minimize the mean and variance of interresponse tımes. Yet the interresponse times of Experiment 1 varied considerably (see Table 2) We decided to see whether the tree-traversal model of Rosenbaum et al (1983) would account for the interresponse times, considering that this model has successfully accounted for such data in previous studies. To test this possibility, we constructed binary trees for each of the choices. We used only binary trees in order to restrict the number of possible trees for each condition; in previous tests of this kind, binary trees have been found to provide a better account of response timing effects than trees that are structurally less restricted (Rosenbaum, 1985) The trees we constructed included an extra node for the choice position ( $1 \mathrm{e}$, a superordinate "choice" node), with two alternative terminal nodes beneath it corresponding to the two possible responses at that serial position We constructed all possible binary trees for each condition and then selected the one for which the best correlation was obtained between the number of nodes and interresponse tımes Next, we averaged the latencies of all nonınitial responses with the same number of immediately preceding node traversals in order to arrive at a best fitting linear function relating the number of node traversals to interresponse times; the slope of this function (1.e, the estimated tıme per node) was $25 \mathrm{~ms}$ We then asked how well the predicted values from this best fitting linear function model fit the interresponse time data of Table 2 The answer was that the predicted values accounted for $974 \%$ of the variance of the interresponse tımes. ${ }^{2}$

Is it contradictory to say that subjects tried to minimize the means and variances of interresponse times even though their actual interresponse times reflected a tree-traversal process? We think not, because the tree-traversal process presumably operates outside consciousness, whereas the scheduling of responses could be based on a consciously monitored quantity such as the raw number of responses before the uncertain response (We shall return to this issue and provide evidence for the latter hypothesis in Experıment 3 )

\section{Experiment 2}

In Experiment 1, when the uncertain response was farther from the end of the sequence, it was also closer to the beginning. Thus, although $T_{1}$ appeared to depend on the number of responses after the uncertain response, it is possible that only the number of "pre-uncertain" responses actually affected $T_{1}$ and that random variation caused $T_{1}$ to appear to depend on the number of "post-uncertain" responses. In Figure I, for example, if the point corresponding to four responses before the uncertain response happened to be slightly elevated because of chance, one would be misled in concluding that the number of responses after the uncertann response affected $T_{1}$. Because the correlation between $T_{1}$ and the number of pre-uncertain responses was quite strong $(-93)$ this possibility must be taken seriously
To resolve this issue, in Experiment 2 we studied sequences that had a variable number of responses after the uncertain response. As Table 3 shows, the number of such responses was two, four, or six We predicted that if $T_{1}$ is truly affected by the number of responses after the uncertain response, $T_{1}$ should increase with this number Of course, we had to make sure that increases of $T_{1}$ with the number of post-uncertain responses were not simply due to the length of the sequence. Therefore, we included Condition $C$, which had the same number of responses as Condition B, but with the uncertain response in a different serial position. Using Equation 3,

$$
T_{1}=s+a e-u d,
$$

the predicted values of $T_{1}$ were

$$
\begin{aligned}
& T_{1}(\mathrm{~A})=s+2 e-2 d, \\
& T_{1}(\mathrm{~B})=s+4 e-2 d, \\
& T_{1}(\mathrm{C})=s+2 e-4 d, \\
& T_{1}(\mathrm{D})=s+6 e-2 d,
\end{aligned}
$$

in which case the four conditions were predicted to follow the inequality

$$
T_{1}(\mathrm{C})<T_{1}(\mathrm{~A})<T_{1}(\mathrm{~B})<T_{1}(\mathrm{D}),
$$

and the differences between conditions were expected to obey the following relations.

$$
\begin{gathered}
{\left[T_{1}(\mathrm{~B})-T_{1}(\mathrm{~A})\right]=\left[T_{1}(\mathrm{D})-T_{1}(\mathrm{~B})\right]} \\
=.5\left[T_{1}(\mathrm{D})-T_{1}(\mathrm{~A})\right]=2 e, \\
T_{1}(\mathrm{~A})-T_{1}(\mathrm{C})=2 d \\
T_{1}(\mathrm{~B})-T_{1}(\mathrm{C})=2 d+2 e, \\
T_{1}(\mathrm{D})-T_{1}(\mathrm{C})=2 d+4 e .
\end{gathered}
$$

\section{Method}

Except for differences necessitated by the set of sequences that were tested, the method was the same as in Experıment 1 Eight Hampshire College students, none of whom had been in other sequence choice experıments, served as subjects

\section{Results and Discussion}

The mean latencies of responses in correct sequences of all conditions are listed in Table 3. (The error rates were $2.7 \%$, 4.3\%, $4.3 \%$, and $5.5 \%$ in Conditions A-D, respectively.) The $T_{1}$ data were analyzed in a one-way ANOVA that evaluated the effect of condition. There was a reliable condition effect, $F(3$, $21)=4.78, p<.02$. The $T_{1}$ means in the four conditions were consistent with the hypothesis that the tıme needed to initiate one of two possible finger sequences depends on the number of

\footnotetext{
${ }^{2}$ The fitting procedure did not include responses that were repetitions of the immediately preceding finger response because those responses would have been significantly slowed by the biomechanical requirements of retracting and then reactivating the same finger
} 
responses after as well as before the uncertain response The means followed the predicted inequality $T_{1}(\mathrm{C})<T_{1}(\mathrm{~A})<$ $T_{1}(\mathrm{~B})<T_{1}$ (D) Furthermore, the differences among the $T_{1} \mathrm{~s}$ in the four conditions were remarkably consistent with Equations 6-9. As predicted by Equation 6, the difference between $T_{1}(\mathrm{~B})$ and $T_{1}(\mathrm{~A}), 19 \mathrm{~ms}$, was virtually identical to the difference between $T_{1}(\mathrm{D})$ and $T_{1}(\mathrm{~B}), 18 \mathrm{~ms}$, which was virtually identical to half the difference between $T_{1}(\mathrm{D})$ and $T_{1}(\mathrm{~A}), 19 \mathrm{~ms}$ On the basis of these values, $e$ could be estımated as $9.5 \approx 10 \mathrm{~ms}$, and on the basis of Equation 7, $d$ could be estımated as $4 \mathrm{~ms}{ }^{3}$ Using these two estimates, the predicted value for Equation $8,28 \mathrm{~ms}$, was virtually identical to the obtained value, $27 \mathrm{~ms}$, and the predicted value for Equation $9,48 \mathrm{~ms}$, was virtually identical to the obtained value, $45 \mathrm{~ms}$ These results support the view that subjects schedule the execution of early responses with reference to the completion of a serial edit pass.

Recall that in Experiment 1 we concluded that interresponse times depended on a tree-traversal process. The analysis of interresponse tımes from Experiment 2 evaluated this same hypothesis. (Given the complexity of the ANOVAs that were needed to fully analyze the interresponse time data because of the differences in sequence length, we analyzed the interresponse times only in terms of the fit of the tree-traversal model ) We constructed binary trees for each condition, and where more than one tree was possible for a condition, we used the better fittıng tree. Following the regression procedure of Experiment 1 , we found that $96.6 \%$ of the variance of the interresponse tıme data of Table 3 was accounted for by the tree-traversal model (The estumate of the time per node traversal was $9 \mathrm{~ms}$, as compared with $25 \mathrm{~ms}$ per node in Experıment 1.) The good fit of the tree-traversal model, taken together with the strong support that the tree-traversal model recelved in Exper1ment 1 and in previous studies (Rosenbaum et al , 1983; Rosenbaum, Inhoff, \& Gordon, 1984), suggests that, in general, rapid finger sequences are executed through hierarchical unpackıng of subprograms.

\section{Experiment 3}

Because the scheduling model assumes that editing goes on while earlier responses are being executed, it allows for the possibility that there may be interactions between editıng and execution. To test this idea, we hypothesized that performance might benefit if the responses between which a choice is made were independent of earlier responses. The sequences we used to evaluate this hypothesis are listed in Table 4 . For half of the conditions, the uncertain and certain responses were performed with the same hand, whereas for the other half the uncertain and certain responses were performed with different hands We assumed that editing would take longer in the same-hand conditions than in the different-hands conditions. This assumption was based on the fact that subjects can choose more quickly between finger presses performed by opposite hands than between finger presses performed by the same hand (Kornblum, 1965; Rosenbaum \& Kornblum, 1982). This assumption can be appreciated by trying the simple experiment of tapping the night middle finger once and then tapping either the same finger, the right index finger, the left middle finger, or the left index finger If one tries to minımıze the delay between the first re-
Table 4

Sequences Studied in Experiment 3

\begin{tabular}{|c|c|c|c|}
\hline \multirow{2}{*}{$\begin{array}{c}\text { Type of } \\
\text { filler }\end{array}$} & \multirow{2}{*}{$\begin{array}{l}\text { Total no of } \\
\text { responses }\end{array}$} & \multicolumn{2}{|c|}{ Startıng and ending hands } \\
\hline & & Different & Same \\
\hline RR & 3 & $\begin{array}{l}\mathbf{R R} m \\
\mathbf{R R} t\end{array}$ & $\begin{array}{l}\operatorname{RR} M \\
\operatorname{RR} I\end{array}$ \\
\hline RR & 5 & $\begin{array}{l}\text { RRRR } m \\
\text { RRRR । }\end{array}$ & $\begin{array}{l}\text { RRRR } M \\
\operatorname{RRRR} I\end{array}$ \\
\hline MR & 3 & $\begin{array}{l}\mathrm{MR}_{2} \\
\mathrm{MR}_{l}\end{array}$ & $\begin{array}{l}\text { MR } M \\
\operatorname{MR} I\end{array}$ \\
\hline MR & 5 & $\begin{array}{l}\text { MRMR } m \\
\text { MRMR }\end{array}$ & $\begin{array}{l}\text { MRMR } M \\
\text { MRMR I }\end{array}$ \\
\hline
\end{tabular}

Note The two sequences between which choices were made are vert1cally arranged within each cell The uncertain responses are italicized Half of the subjects had the sequences listed here, and half had the leftright mirror image of these sequences (e $\mathrm{g}, \mathrm{rr} m$ vs $\mathrm{rr} l$, etc ) The letters denote key presses made with the following fingers $1=$ left index, $m=$ left middle, $M=$ right middle, $r=$ left ring, $R=$ right ring

sponse and second, the trajectory of the first response is far more affected by which finger of the same hand is used than by which finger of the other hand is used This indicates that the programming of finger taps is more sensitive to identities of later same-hand responses than to identities of later differenthands responses The implication is that in the present experiment, a longer edit pass should be necessary in the same-hand conditions than in the different-hands conditions. Therefore, according to the idea that scheduling is done with reference to the completion of the edit pass, $T_{1}$ should be longer in the samehand conditions than in the different-hands conditions ${ }^{4}$

A second issue addressed in Experiment 3 concerned the type of information subjects use to schedule responses One possibility is that only the number of responses before the uncertain response is used to schedule the initiation of preceding re-

\footnotetext{
${ }^{3}$ It is surprising that these parameter estimates are so small In part, the small values may be attributable to subject differences, although the largest estımate of $e$ for any subject was $40 \mathrm{~ms}$ and the largest estımate of $d$ for any subject was $18 \mathrm{~ms}$ We cannot explain why the estımates are so small, however, our faith in the model is restored by the fact that the relations among mean $T_{1} \mathrm{~s}$ in the four conditions agree almost perfectly with the model's predictions

${ }^{4}$ Another possibility is that the edit pass starts at an earlier serial position in the same-hand conditions than in the different-hands conditions This would be the case if the effective point of uncertainty came before the nominal point of uncertainty Allowing the edit pass to start at the effective point of uncertainty $(1 \mathrm{e}$, the first point in the sequence at which performance could differ, even subtly, depending on the choice signal) provides the HED model with a mechanism for producing anticipatory effects in performance, such as those seen in typewriting (Shaffer, 1978, Vivianı \& Terzuolo, 1980) and speech (Fowler, 1980, Kent, 1983) The original HED model lacked a mechanism that could account for antıcipatory effects, because editıng was assumed to proceed unidirectionally from the nominal point of uncertainty to the end of the sequence The unidirectional editing assumption can be retained and anticipatory effects produced if editing is allowed to begin at the first point in the sequence at which performance may differ depending on the identity of the choice signal
} 
sponses The other possibility is that anticipated delays between early responses, as well as the number of such responses, are used for scheduling To address this issue, in Experiment 3 we used filler responses that we thought would be produced at different rates One type of filler response was the repeated finger press (RR, ), the other was the repeated couplet MR, $M R$, .) Repeated responses are usually performed more slowly than alternatıng responses (as was indeed the case in Experiment 1) Therefore, we expected subjects to produce the repeated couplets more quickly than the repeated finger presses The question, then, was whether the difference in response rate would enter into the scheduling process

Figure 2 lllustrates the two possible outcomes. In Figure 2a, the delays between filler responses are not taken into account; instead, only the number of filler responses is used in scheduling Under this condition, the first response is scheduled to occur at a tume that depends only on the number of responses before the uncertan response; the fact that the pre-uncertan responses are produced at different rates is not taken into account The result is that the fast and slow responses are centrally initzated at the same time, but the observed $T_{1}$ is shorter for the fast responses. In the present experiment, therefore, if subjects use only the number of pre-uncertain responses for scheduling, $T_{1}$ should be shorter when the fillers are alternating finger responses than when the fillers are repeated presses of the same finger. A corollary prediction from Figure $2 a$ is that the latency of the uncertain response should be elevated for the responses that are produced at a fast rate (alternating finger presses) as compared with the responses that are produced at a slow rate (repeated presses of the same finger).

In Figure $2 b$, the delays between filler responses are taken into account In this situation, because the subject schedules the pre-uncertain responses so that the means and variances of interresponse times are minimized to $d, T_{1}$ should be longer for the responses that are produced more quickly ( $1 \mathrm{e}$. , the couplets) than for the responses that are produced more slowly (1.e, the single finger repetitions), which is the opposite of what was predicted in Figure 2a.

The final factor manıpulated in Experiment 3 was the length of the sequence. We varied this factor to replicate the inverse length effect of Experiment 1

\section{Method}

The method was the same as that used in the previous experiments. except that a new group of 8 Hampshire College students served as subjects

\section{Results}

\section{Inulal Response Times}

Figure 3 shows mean $T_{1}$ data (from errorless trials on the second day only) for the eight types of sequences An ANOVA applied to these data evaluated the effects of sequence length (three or five responses), type of response fller ( $R R$ or MR), whether the last response used the same hand as the starting responses, and whether the last response used the middle or index finger There was a statustically significant effect of the relaton between the starting and ending hand, $F(1,7)=7.55, p<$ (a)
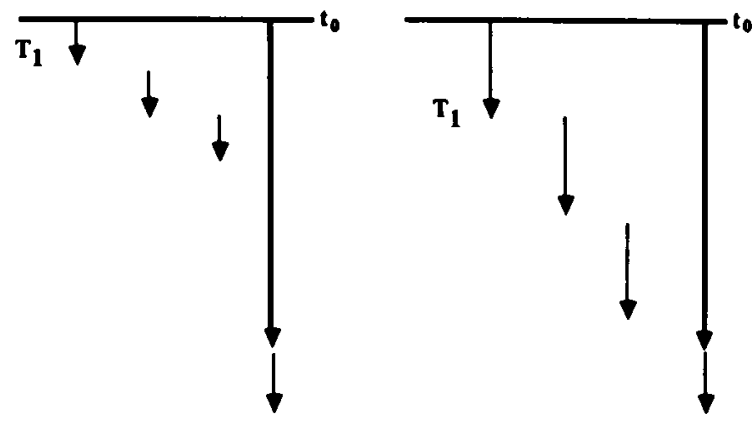

(b)
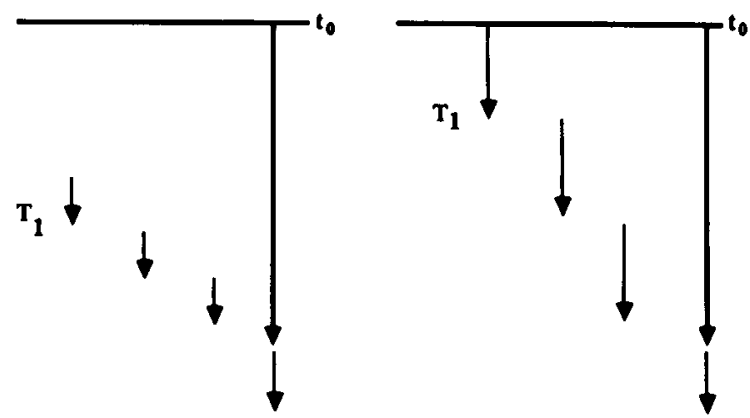

Figure 2 Two methods of scheduling responses (Thick arrows represent programming delays [encoding plus editıng] after the reaction signal is presented [at time $t_{0}$ ] Thin arrows represent execution delays Long thun arrows represent long execution delays [slow responses], whereas short thin arrows represent short execution delays [fast responses] When execution delays are not taken into account [Panel a], $T_{1}$ is predicted to be shorter for fast responses than for slow responses, but when execution delays are taken into account [Panel b], $T_{1}$ is predicted to be shorter for slow responses than for fast responses )

03, mean $T_{1}$ was longer when the last response used the same hand as the starting responses $(331 \mathrm{~ms})$ than when the last response used the other hand $(307 \mathrm{~ms})$. The effect of sequence length approached statistıcal significance, $F(1,7)=3.87, p<$ .09 , five-response sequences ( $303 \mathrm{~ms}$ ) were started more quickly than three-response sequences $(336 \mathrm{~ms})$. There was also a significant interaction among all four factors, $F(1,7)=978, p<$ 02 ; mean $T_{1}$ was shorter for sequences beginning with $M R$ than $R R$, but only when the starting and ending responses were performed with different hands, and the benefit of beginning samerather than different-hand sequences was smaller when the in1thal couplet was $R R(12 \mathrm{~ms})$ rather than $M R(36 \mathrm{~ms})$. No other main effects or interactions approached statsstical significance; all corresponding $p$ values exceeded 20

\section{Interresponse Times}

Mean interresponse times from errorless trials of the second day appear in Table 5. We used an ANOVA to evaluate the effects of sequence length (three or five), type of filler response (RR or $M R$ ), and the relation between the initial and final responses (same or different hands). This ANOVA revealed a mann effect of 


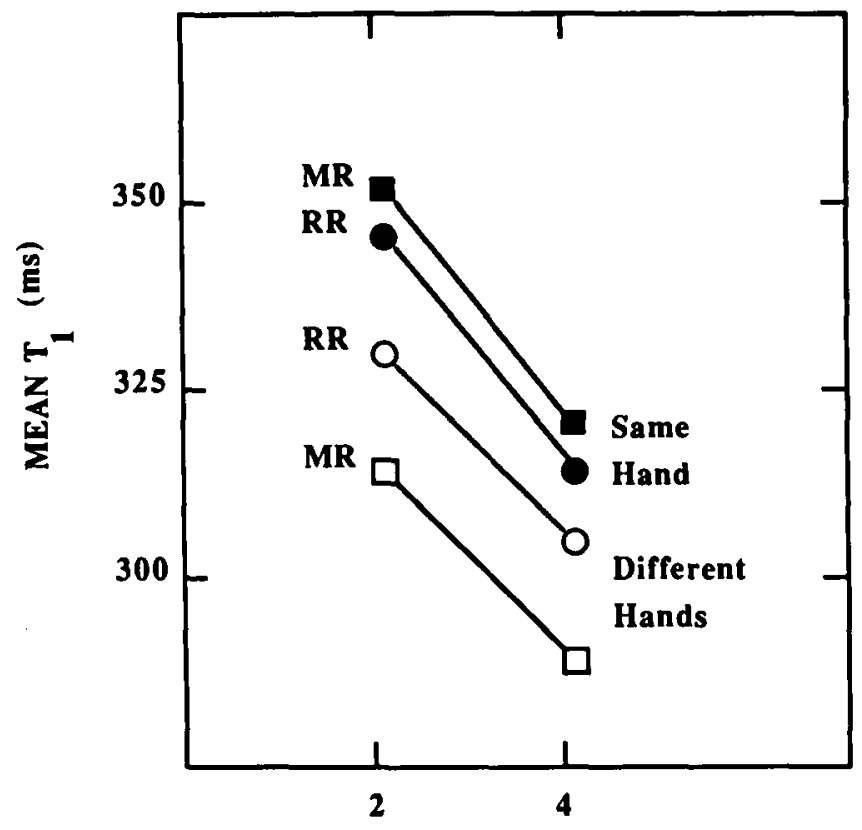

NUMBER OF RESPONSES

\section{BEFORE UNCERTAIN RESPONSE}

Figure 3 Mean latency $\left(T_{1}\right)$ of the first response in Experıment 3 ( $M R$ and $R R$ refer to the two types of filler responses )

sequence length, $F(1,7)=2747, p<001$, five-response sequences were performed $28 \mathrm{~ms}$ more slowly than three-response sequences. There was a marginally significant effect of type of response filler, $F(1,7)=4.17, p<.08$; RR sequences were performed $18 \mathrm{~ms}$ more slowly than MR sequences. There was also a marginally significant effect of the relation between the initial and final responses, $F(1,7)=3.88, p<09$, interresponse tımes were $8 \mathrm{~ms}$ slower for same-hand sequences than for different-hands sequences. No interactions approached statıstıcal sıgnificance.

As in the previous experıments, we also determined whether the tree-traversal model accounted for the interresponse time data. Our method for fitting the model was the same as in Experiments 1 and 2 We found that the model accounted for $984 \%$ of the variance in the data of Table 5 The estimated time per node was $27 \mathrm{~ms}$

\section{Errors}

Errors occurred on $8 \%$ of the trials on the second day of the experiment; errors on the first day were not studied An ANOVA revealed that more errors, $F(1,6)=1213, p<.02$, occurred in the longer sequences ( $101 \%$ ) than in the shorter sequences $(67 \%)$. There were no other main effects or interactions involving sequence length, startıng hand (left or right), endıng hand (left or right), or type of filler response

\section{Discussion}

The results of Experiment 3 support the scheduling model As predicted by the model, $T_{1}$ decreased as the distance from the beginning of the sequence to the uncertain response increased Although this decrease was not quite significant by conventional standards, the trend in the data replicates our Experıment 1 as well as the third experıment of Rosenbaum, Inhoff, and Gordon (1984) and therefore attests to the generality of the effect

As predicted by the scheduling model, $T_{1}$ was shorter when different hands were used for the startung (certain) and ending (uncertain) responses than when the same hand was used for these two kinds of responses It is unlikely that this result was just an execution artifact because simple RTs to begin typewriting sequences have been found to be longer for sequences that cross hands than for sequences that use only one hand (Sternberg et al , 1978), which is the opposite of what we observed here. The fact that $T_{1}$ was reduced in the different-hands conditions fits with the assumption that subjects chose forthcoming responses while performing earher responses If subjects had not used this method, $T_{1}$ would not have depended on the relation between the early, certain responses and the later, uncertain responses.

The results of Experiment 3 also suggest that subjects used the number of responses, but not the probable delays, between responses in scheduling their pre-uncertain responses Recall

Table 5

Mean Interresponse Times (in Milliseconds) Obtained in Experiments 3

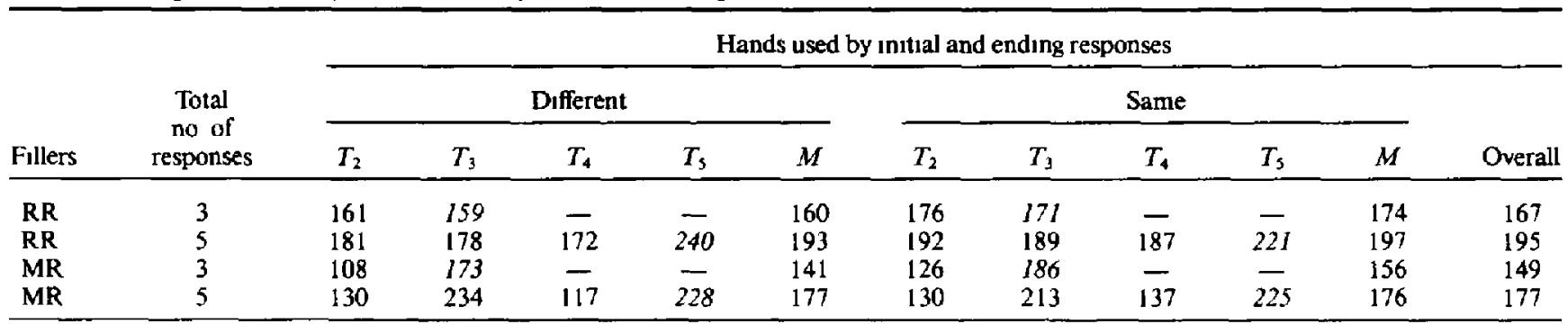

Note Italics denote initially uncertain responses The letters indicate key presses made whth the following fingers $M=$ right middle and $R=$ right ring $T_{2}-T_{5}$ mean latencies of the 2 nd-5th responses Dashes indicate undefined latencies, that 15 , latencies for responses past the end of the sequence 
that to address this issue, we varied the type of filler responses, expecting repeated couplets (MR, MR, . .) to be produced more quickly than repeated single finger presses (RRR . . ) Consistent with our expectation, repeated couplets were performed more quickly (mean interresponse time $=163 \mathrm{~ms}$ ) than repeated single finger presses (mean interresponse tıme $=181$ $\mathrm{ms}$ ), although this difference was only marginally significant. Given this outcome, it was meaningful to ask whether the $T_{1}$ data conformed to the predictions of Figure 2a, which assumed that delay information is not taken into account, or the predictıons of Figure 2b, which assumed that delay information is taken into account The data conformed more closely to the predictions of Figure 2a. As predicted in Figure 2a, $T_{1}$ was shorter for the sequences with fast filler responses (MR) than for the sequences with slow filler responses (RR), although this difference held up only in the different-hands conditions. (The apparent $T_{1}$ difference beteen $\mathrm{MR}$ and $\mathrm{RR}$ sequences in the same-hand conditions [see Figure 3] was not statistically significant.) Another result that supported the predictions of Figure $2 \mathrm{a}$ was that the latency of the initially uncertain response was longer for the fast (MR) sequences than for the slow (RR) sequences This prediction was supported in the same-hand sequences and in the three-response different-hands sequences, although it was not supported in the five-response differenthands sequences. At this point, we do not understand why the predictions of Figure 2a were only partially supported, but insofar as they were supported more consistently than the predictions of Figure $2 b$, we are led to conclude that subjects used only the number of pre-uncertain responses to schedule their responses

\section{General Discussion}

We have described three experiments that used the sequence choice procedure in order to shed light on human motor programming. The experıments were motivated by our concern that the hierarchical editor (HED) model of Rosenbaum, Inhoff, and Gordon (1984) does not limit the span of programming Thus, it predicts (inadvertently) that choices between very long response sequences could take an inordinately long time to complete We considered two possible solutions to this problem. One is that subjects break programs into chunks and apply the HED procedure to one chunk at a time (the discrete solution) The other possibility is that subjects begin executing the program while continuing to edit later parts of the program (the contınuous solution). The evidence favored the contınuous solution Specifically, the data supported a model in which subjects prepare for a choice between two response sequences by working backward from the projected time to complete editing of the entire sequence The purpose of working backward in this way is to schedule the execution of the first response so that the mean and variance of interresponse times are minimized. When the chorce between sequences is actually required-that is, when the choice signal appears-the subject immediately Identifies the signal and begins editing the program from the first uncertain point onward, as assumed in the original HED model Meanwhile, the subject waits until the scheduled time to begin executing the sequence, and when that time arrives, begins to execute the sequence in the manner assumed in the original HED model, that is, through a tree-traversal process One limitation of the scheduling process is that it appears to take account of the number of responses before the uncertain response but not the pattern of delays that are likely to occur between those responses during execution

As the abovementioned description shows, the scheduling model preserves most of the assumptions of the HED model. It assumes that there is an editing process that begins with the first uncertain response and proceeds to the end of the sequence. In addition, it assumes that there is a hierarchical execution process. The only assumption in the scheduling model that is not part of the HED model is that execution begins while editing is still going on (rather than afterward, as assumed in the HED model). By allowing execution and editing to run simultaneously, the scheduling model helps solve the problem of protracted delays during choices between long sequences: When the number of responses before the first uncertain response is large enough, the edit interval is filled with pre-uncertain responses

The scheduling model still faces a problem, however. It predicts that $T_{1}$ should continue to increase with $a$, the number of responses after the first uncertain response. One can solve this problem by recognizing that some structural factors must determine whether an edit pass is necessary or even possible Presumably, when two sequences are extremely different, it is easier to keep their representations apart and to choose between them at the level of therr top (root) nodes than to mix the representations and rely on an edit pass through that single representation For example, an edit pass might be used to choose between the first few notes of two piano concertos, but it is unlikely that an edit pass would be used to choose between the first few notes of one piano concerto and the first few steps of a ballet routine. By the same token, because it would be extremely difficult to fit the representations for two very long sequences of the same type into a single representation-would one fit representations of two prano concertos together on a note-by-note basis, for example? - it would clearly be preferable to keep the representations separate rather than to try to combine them. Editing would only be useful, then, for choices between sequences that can reasonably be expected to share the same representation. As the possible sequences become sufficiently long or different, editing would no longer and performance. Thus, for two simular sequences of variable length, editing would be useful only up to a point; adding responses beyond that point would no longer affect the length of the edit pass, and so the time needed to initiate the sequence would no longer increase as more of those responses were added. On this analysis, both the discrete and continuous models are partly correct. The programming system edits responses withın discrete spans, but within those spans, editıng and execution can occur contınuously according to schedules that are establıshed in advance

\section{References}

Bahıll, A T, \& LaRıtz, T (1984, May-June) Why can't batters keep their eyes on the ball' American Sclentıst, 72, 249-253

Fowler, C (1980) Coarticulation and theories of extrinsic tımıng Journal of Phonetics, 8, 113-133

Henry, F. M , \& Rogers, D E (1960) Increased response latency for complicated movements and a "memory drum" theory of neuromotor reaction Research Quarterly, 31, 448-458 
Hulstıjn, W \& van Galen, G P (1983) Programming in handwritıng Reaction time and movement time as a function of sequence length Acta Psychologica, 54, 23-49

Inhoff, A W (1986) Preparing sequences of saccades under choice reaction conditions Effects of sequence length and context Acta Psychologica, 61, 211-228

Kent, R D (1983) The segmental organization of speech In P F MacNetlage (Ed), The production of speech (pp 57-89) New York Springer-Verlag

Klapp, S T, Wyatt, E P, \& Lingo, W M (1974) Response programming in simple and choice reactions Journal of Motor Behavior, 6 , 263-271

Kornblum, S (1965) Response competition and/or inhibition in two choice reaction time Psychonomic Science, 2, 55-56

Lenneberg, E H (1967) Biological foundations of language New York Wiley

Logan, G D (1983) Time, information, and the varıous spans in typewritıng. In W E Cooper (Ed), Cognitlve aspects of skilled typewriting New York Springer-Verlag

McClelland, J L (1979) On the time relations of mental processes An examination of systems of processes in cascade. Psychological Review, 86, 287-330

Monsell, S (1986) Programmıng of complex sequences Evidence from the timing of rapid speech and other productions In C Fromm \& $\mathrm{H}$ Heuer (Eds), Generation and modulation of action patterns (pp 7286) Berlın Sprınger-Verlag

Rosenbaum, D A (1985) Motor programming A review and scheduling theory In $\mathrm{H}$ Heuer, $\mathrm{U}$ Kleinbeck, \& $\mathrm{K}$-M Schmidt (Eds), Motor behavior Programming, control, and acquisition (pp 1-33) Berlin Springer-Verlag

Rosenbaum, D. A , Hindorff, V., \& Munro, E M (1986) Programming of rapıd finger sequences In C Fromm \& $\mathrm{H}$ Heuer (Eds), Genera- tıon and modulation of action patterns (pp 64-71) Berlın SprıngerVerlag

Rosenbaum, D A , Inhoff, A W, \& Gordon, A M (1984) Choosing between movement sequences A hierarchical editor model Journal of Expenmental Psychology General, 113, 372-393

Rosenbaum, D A, Kenny, S , \& Derr, M A (1983) Hierarchical control of rapid movement sequences Journal of Expertmental Psychology Human Perception and Performance, 9, 86-102

Rosenbaum, D A , \& Kornblum, S (1982) A priming method for investıgating the selection of motor responses Acta Psychologica, 51 . 223-243

Rosenbaum, D A , Saltzman, E , \& Kıngman, A (1984) Choosıng between movement sequences In S Kornblum \& J Requin (Eds), Pre. paratory states and processes (pp 119-134) Hillsdale, NJ Erlbaum

Shaffer, L H (1978) Timing in the motor programming of typing Quarterly Journal of Experimental Psychology, 30, 333-345

Sternberg, S (1969) The discovery of processing stages Extensions of Donders' method In W G Koster (Ed), Attention and performance II (pp 276-315) Amsterdam North-Holland

Sternberg, S, Monsell, S, Knoll, R L, \& Wright, C E (1978) The latency and duration of rapid movement sequences Comparisons of speech and typewriting In G E Stelmach (Ed), Information process. ing in motor control and learning (pp 117-152) New York Academıc Press

Vivianı, P, \& Terzuolo, C (1980) Space-tıme invariance in learned motor skills In G E Stelmach \& J Requin (Eds), Tutorials in motor behavior (pp 525-533) Amsterdam North-Holland

Zıngale, C , \& Kowler, E (1985) Programming sequences of saccades Investigative Opthalmology and Vision Sctence, 26, 48

Received May 27, 1986

Revision received September 9, 1986 